\title{
How much can societal turning points affect forecasts' accuracy in Europe? Case of post-communistic transformation in Slovakia and the Czech Republic
}

\author{
Branislav Bleha
}

\begin{abstract}
It seems that the least accurate (population) forecasts are those published in the period of great historical turning points both economic and political. Several studies analysed the forecasts' accuracy in Western countries, but the post-1990 development in the post-communistic countries has not been analysed in this respect. The general goal of the study is to show how hardly predictable and poorly predicted the demographical processes have appeared to be during the major societal and economic turning points after the post-communistic transformation started. To do this, the study first provides an exact measurement of the forecasts' accuracy in transitioning Slovakia and Czechia. The key finding is that the forecasters either did not recognise the beginning of somewhat completely "new" or underestimated the dimensions of the turning points and turns in the recent trends. Thus, the assumption "drag" shows up much more frequently than some kind of over-reaction. Implicitly, the research re-opens a perpetual question whether methodological-mathematical improvements are more (or less) important than the deep insight into the forecasted processes. Secondly, the study demonstrates the range and dimension of changes that impact the demographic present and future. Here, the alternative future is built and simulated in terms of what the populations would have looked like if the socialist system had not collapsed. It is a quite simple but very smart way how to demonstrate the range of turnover since 1989.
\end{abstract}

Keywords: Czech Republic, Slovak Republic, Transformation, Accuracy, Simulation, Turning point

\section{Introduction-background and research questions} The absolute majority in the set of current demographical and subsequent economic forecasts goes from the irreversible population ageing all over the world. Europe is a leader in this negative trend. The opposite opinions in the demographic debate practically do not exist. But should we be so sure in this concern? We try to demonstrate the potential uncertainties and show examples from the past that brought a lot of surprising and unexpected developments. The political changes in Europe around 1990 started a transformation, social changes and fast demographic changes. A reduction in fertility and an increase in life expectancy significantly altered the demographic trajectory. These are known facts,

Correspondence: branislav.bleha@uniba.sk

Faculty of Natural Sciences, Comenius University in Bratislava, Ilkovičova 6, 84215 Bratislava, Slovak Republic

analysed by hundreds of studies. We know that the impact of changes on the population dynamics was massive, but European populations faced such big turning points regularly throughout the twentieth century. After the WW2, the UN Population division and some other institutions and national authorities started to publish population forecasts regularly. The forecast methods and practice and partly also their accuracy and limits have become a subject of numerous studies mostly in the last quarter of the twentieth century, with many fresh studies having appeared in the new millennium, too. These studies have mostly focused on both how to evaluate and what indicators are appropriate for the evaluation. The key and principal questions involve the accuracy factors, appropriateness of a method or model applied, length of the forecasting period and improvement of knowledge on demographic processes. New 
methods based on adjusted fertility rates [1] may, for instance, lead to better understanding and forecasts of future fertility. Such methods were not available until the 1990s. In one of his principal study, Keyfitz [2] points out the role of forecasts' accuracy and subjective individuality of the forecaster. At the same time, he emphasises improvements of UN forecasts throughout the decades following WW2. He also seeks the reasons for those improvements, though their relevancy or weight remains uncertain. Among them, he mentions a methodological upgrade versus weaker oscillations or unexpected shifts versus knowledge improvements. Stoto [3] comments on the accuracy of American forecasts in the context of confidence intervals, applied methods and forecast period length and clearly distinguishes between projections (simulations) and forecasts expressing subjective attitudes of the forecaster towards the future. We point out that in our empirical case no forecast was produced and we produced only simulation using postdiction and projection (see the "Data and methods" section). The abovementioned concepts are often misinterpreted even today by both forecasters and users of the forecasts. The alternative scenarios demonstrated in the second part of this study represent an alternative, virtual future, i.e. they represent a projection. Smith [4] highlights the relevancy of confidence interval creation using the sets of empirical forecasts for nearly 3000 counties in the USA. What is now a common method was only being introduced then.

A fruitful debate on forecasts concerning their reliability and accuracy appeared in the 1990s. After all, the debate resulted in the development of stochastic or probabilistic approaches applied in population forecasts. One of the principal issues was an examination of forecast accuracy concerning the forecasting period length, error progress in time and mainly methods applied. On the one hand, Smith and Sincich [5] confirm a linear or almost linear relationship between accuracy and forecast period length, but no significant relationship between bias and length of the horizon. The same authors [6] illustrate by US state forecasts that complex and sophisticated techniques bring neither more accurate nor less biased results compared to simple techniques such as naive models. As shown by Sanderson [7], the use of a wide $95 \%$ confidence interval does not guarantee that the results will be within the interval. Stochastic methods witnessed a rapid boom in the 1990s and in the first decade of the new millennium, accompanied by the development of methods using accurate prediction intervals, such as ARIMA application [8]. Regardless of the expansion of these methods including the ARIMA model and probabilistic methods, the issue of factors affecting inaccuracy is still on the table. Do better models generate more accurate forecasts? Although Rogers [9] does not cast doubt upon previous examinations, he emphasises that reality is probably more sophisticated, and the forecast results do not reflect only models applied but also depend on the moment when the model is being applied. This is a very important part of the story. A complex overview of forecasts for industrialised countries was made by Keilman [10]. Keilman and Kučera [11] bring an interesting comparison of the forecasts' accuracy in the Netherlands and Czechoslovakia. They clearly showed that advancement in the methodology and the overall quality of demographic research (being higher in the Netherlands) did not correlate with the accuracy and the situation at the time of publication is very important. As they assessed, the very first afterWW2-forecasts published in the 1950s (in case of the Netherlands) underestimated the level of fertility because the post-war baby-boom was even stronger than expected, unlike the later ones from the period of around 1967-1972, which were too optimistic because of downward trends in fertility. But one really ought to distinguish between the post-war "baby-boom" effects and later decrease that seems to be stronger just thanks to the post-war effects died away. On the other side, some changes seem to be cardinal (definitive belowreplacement-levels of the TFR and some others). It might be extracted from the Dutch results that the forecasters realised their excessive optimism towards fertility only around 1975 (and later), although fertility had been dropping at least for 6-7 years earlier. The errors in the number of births are much lower in later forecasts, for instance in that from 1980, although there is still a slight overestimation. What should be really stressed is that, actually, some forecasts published in the 1950s underestimated fertility just after 5 years (since their publication), whereas the overestimation is fact after 20 years. Thus, the length of an evaluating period matters especially when turns are frequent and this is just the case of the decades after WW2. Similarly, profound and rapid changes have been observed in former communist countries. However, no complex research has shown how the forecasters overcame the most powerful demographic changes of the 1990s. Thus, our first aim is to reveal how successful the forecasters were to cope with the turning moment, the new social and economic conditions and overall society transformation, examining a selection of subnational forecasts.

The latter goal arises from the fact that many studies tried to explain the changes in family and reproduction behaviour in the post-communistic countries; however, the changes in the dynamics and ageing were not precisely quantified so far. By now, it has not been shown how the fall of the socialist regimes altered the previous trajectory and to what extent it accelerated ageing and depopulation. Thus, a simulation is aimed to quantify 
the deviations between a "communistic" trajectory to be prolonged far beyond 1989 and the actual after-1989 trajectory. Like in the first goal concerning the accuracy, a comparison of the Slovak and Czech Republics has been used also in the second goal. The major reason is that several similarities as well as differences are appropriate for studying these countries. It has been confirmed that demographic development is lagging behind in Slovakia, and transformational changes and timing changes (postponement and then recuperation) manifested in the Czech Republic somewhat earlier [12]. This was also the case during the demographic transition in the nineteenth and twentieth centuries. It began later in Slovakia and was finished faster. On the other side, both countries shared the same political regime and, until 1989, they were part of the same state. They differed in part from a socio-developmental perspective. Slovakia has always shown a higher proportion of workers in agriculture but also higher religiousness according to census data, a greater percentage of the Roma population often socially segregated $[13,14]$, and substantial immigration to the Czech Republic during the existence of the common state. Even after 1989, the Czech Republic remains somewhat stronger economy with lower unemployment and a higher figure of GDP per capita according to recent EUROSTAT data, although Slovakia, for example, adopted the Euro currency earlier, introduced pension reforms and attracted many major investors.

\section{Data and methods}

Concerning the first goal focused on forecast accuracy examination, two subnational forecasts $[15,16]$ were analysed. Both forecasts were generated in the period of the most dynamic changes in some of the demographic processes. The subnational forecasts were used to show some spatial accuracy aspects, spatial forecast errors distribution and effects of inner migration. The latter witnessed completely new phenomena such as amenity migration and suburbanisation, above all. Such processes were reported in Western Europe a few decades before, but they were quite new for countries such as former Czechoslovakia. Were the forecasters capable to predict their rapid emergence and were their predictions finally adequate?

Two basic indicators of accuracy were applied, similarly to some previously released studies focused on forecast accuracy evaluation. Of course, there is a variety of more complicated and sophisticated indicators (see for instance [17]) especially assessing subnational or multistate forecasts. The following measures are adequate for our purposes. One of the elementary indicators is the percentage error (PE) expressing a relative difference between real and forecast values in per cent. The mean percentage error (MPE) is a combination of several percentage-error values such as medium representing age categories (in age-structural analysis) or medium error in a set of territorial units; in this case, local administrative units LAU 1 (districts) were considered. By analogy, absolute percentage errors and consequently mean absolute percentage errors are calculated. As for the percentage errors, the deviations are both positive and negative, and mean error may also reach positive as well as negative values. This indicates the direction in which the forecast is wrong and whether the general forecast is under- or overestimated.

The latter goal includes a comparative simulation of theoretical and real demographic scenarios until 2018 and predicted subsequent demographic trends until 2040. We used the currently existing national forecasts published by official institutions in the Czech Republic [18] and Slovakia [19]. We used the medium scenarios. These scenarios represent the benchmark against which we compare the theoretical simulation. The simulation demonstrates what development would have been like if the social and demographic changes had not occurred after 1989. Thus, we tried to simulate what development would have been if the values had been "frozen" at the level of 1989. The simulation has its starting point in 1989 , i.e. at the beginning of the political and social changes.

For the simulation purposes, data of the year 1989 were used. It is the last year of the communist regime. The quantum and tempo of fertility and mortality that were actual in 1989 were used for the calibration of the prediction model. The age structure as of December 31, 1989, was used; that date is the starting point for the projection. From this point until the forecast horizon (2040), the model was calibrated every year using the same values, the data valid for 1989 . The results therefore represent a hypothetical age structure of both countries if a rapid after-1989 transformation of reproductive behaviour did not occur.

It should be noted that already in the 1980s, during the socialist era, there was a change in reproduction behaviour, fertility and mortality. The measures of communist governments, temporarily affecting an increase in fertility in the 1970s (but only briefly), lost their potential. It is interesting that even in the 1970s a temporary increase in fertility first occurred in the Czech Republic and with a certain delay in Slovakia. Also noteworthy is the fact that in the first 2 years after the change of the regime in the Czech Republic (first 4 years in the case of the Slovak Republic), the total fertility rate remained at the initial level, and only then an enormous decline came. It is likely that, even assuming a continuation of the communist establishment, there would be some further changes in reproduction. However, it is difficult to estimate exactly what these changes would be. 
Very likely, they would certainly be only moderate and not so major as they actually were during the transformation. So, in a simplified way, we used precisely the values of 1989 as the last pre-transition year and we used a naive extrapolation model for the projection. Moreover, these values are close to the replacement level of fertility. This helps demonstrate how the shift from the replacement level to lowest-low fertility affected and will affect ageing and depopulation in the decades following 1990. At the same time, there are certain differences in total fertility between the Czech Republic and Slovakia, which helped uncover the extent to which these, at a first glance, relatively small differences influenced the differentiation (differences) of trajectories in these countries after 1989. The common cohort-component model was used for prediction. The age-specific fertility rates and probabilities of deaths for both sexes are the major inputs, migration has not been incorporated.

Figure 1 explains the basic idea of the simulation. As a starting point for simulation, the "revolutionary" year 1989 is set. From this starting point, the actual and forecasted demographical developments are compared to those simulated using both the post-diction and projection. The period of the last three decades could be simply called as a period of transformation, and the future development as the post-transformation period, although they are different opinions when the societal transformation did finish. In terms of demographic reproduction, the last decade is a "calming period" in which the radical turns in trends have damped out and many indicators such as non-marital births or timing of fertility touch the levels in the Western countries. On the other side, there has been still the phase of recuperation, at least in some local populations, and the childlessness is predicted to grow. Hence, the end of transformation can only be estimated very roughly. From 1989 to the present time, we simulated the three decades of alternative history (no transformation, the communist regime remained). But this is not the end of the story. Our simulation is going also onward to the future, and in case of future predictions, the term projection is accurate. We used the past to project the future, whereas the retrodiction means using the future to predict the past, but this is truly not our case. Retrodiction and post-diction generally are the forms of "reconstructions of history" moving backward from the present to the past, or from the past to the present $[20,21]$. Both the retrodiction and post-diction are sometimes used freely as the synonyms. Our simulation represents a postdiction in the period from 1989 to 2018 and a projection (projecting the future) in the period 2019-2040.

Table 1 provides information on parameters entering the model. The simulated $1989-2040$ period is calibrated using real official values of the year 1989, the last year of the communist era. For the population of Slovakia, therefore, fertility on the replacement level is by about 0.2 children higher than that of the Czech Republic. Historically, the values in the Czech Republic were lower. The difference is slight only; however, it plays a role in the results. As for the timing of fertility, the curve of age-specific fertility rates is much more asymmetrical, because of concentration of births in the younger ages. The mean age at first birth was 21-22 years only, whereas current values are by 5-6 years higher. One should point out that not only the quantum (intensity) but also the tempo (timing) plays a role and was taken

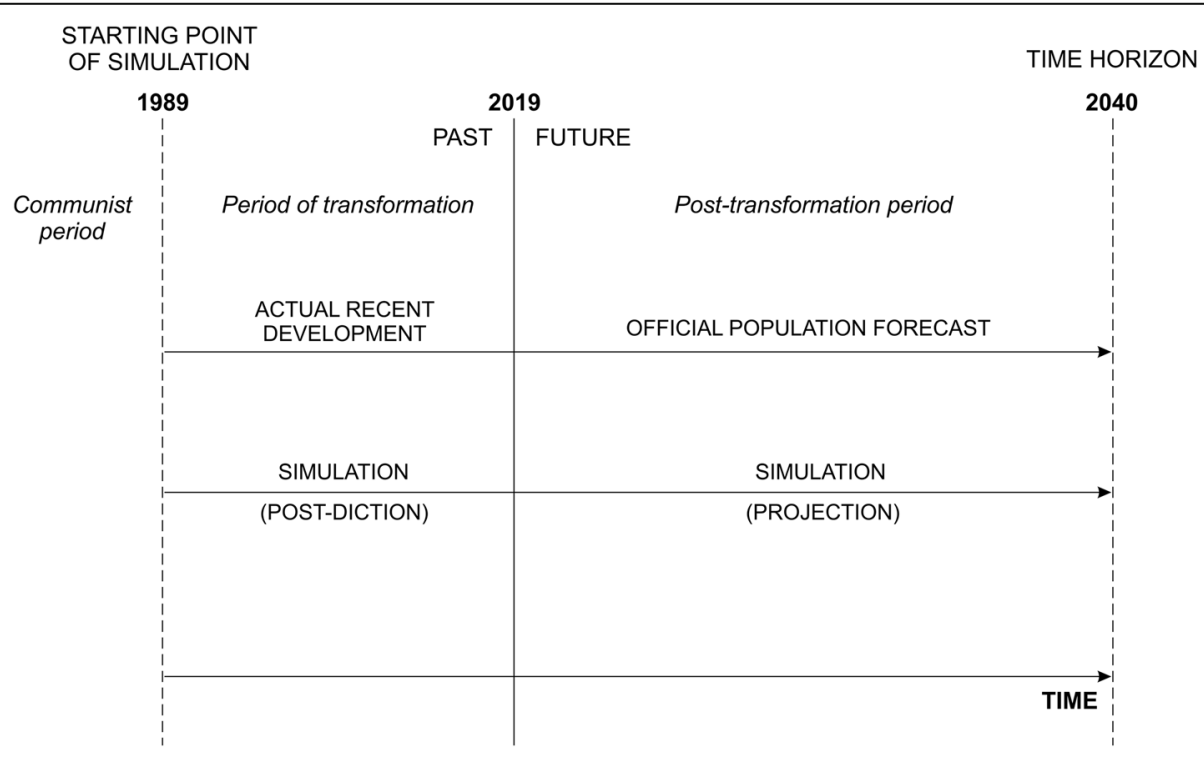

Fig. 1 The conceptual framework of the simulation. Source: authors 
Table 1 Overview of values of the total fertility rate in selected years

\begin{tabular}{lllllll}
\hline & Real data, 1950 & Real data, 1989 & Real data, 2015 & $\begin{array}{l}\text { 1989-2018, simulation: } \\
\text { post-diction period }\end{array}$ & 2040, official forecast & $\begin{array}{l}\text { 2019-2040, simulation: } \\
\text { projection period }\end{array}$ \\
\hline Czech R. & 2.80 & 1.87 & 1.46 & 1.87 & 1.53 & 1.87 \\
Slovak R. & 3.56 & 2.08 & 1.34 & 2.08 & 1.59 & 2.08 \\
\hline
\end{tabular}

Source: $[18,19]$, Czech Statistical Office, Statistical Office of the Slovak Republic, own simulation

into consideration. For instance, the share of realised fertility in 1989 was approximately $45 \%$ in Slovak women aged 20-24, but the value dropped to less than $20 \%$ in 2017. There is also some inter-generational shift in reproductive behaviour based on which cohorts and in which age faced the starting of transformation [22].

We only extract the assumptions and results of official forecasts. The forecasts also used the common cohortcomponent method, so they are comparable. We have used the forecasts published by official statistical bodies in both countries. They estimate a fertility level roughly at the level of 1.5 to 1.6 children in both countries in 2040. The data from the past confirm a certain "delayed pattern" in the case of Slovakia. At the same time, there is a certain space for higher levels of fertility in Slovakia due to the representation of the Roma population and higher religiosity in Slovakia. According to the results of the national population census in 2011, the share of believers in Slovakia was $76 \%$, while the Czech Republic is very likely the most atheistic country in Europe with a 32\% share merely.

The values of life expectancy at birth grew before 1989, but very slowly (Table 2). In the case of males in Slovakia and the Czech Republic, it even stagnated (or grew more or less negligibly) for a very long time, from the mid-1960s until the change of the political regime in 1989. For women, it increased only slightly and thus the difference between male and female values of life expectancy widened. For mortality, the impact of social changes is completely obvious. An analysis of avoidable mortality in the case of Slovakia speaks clearly. After 1989, its level fell sharply in connection with changes in healthcare, emergency rescue, environmental improvement, employment structure (less industry) and others. For example, in the 1993-1997 period, 53 of the 79 districts of Slovakia recorded annually more than 5 avoidable deaths of males per 1000 European standard population. In the 2009-2013 period, not even in one of the 79 districts did it exceed this value. It can therefore be assumed that in the case of continuation of the communist establishment, at least male mortality would stagnate or increase only slightly. Both tables illustrate a clear gap between expected development and "frozen" development, although in the case of fertility an expected increase of the TFR means convergence between simulated and forecasted values. It should be stated that the medium scenarios seem to be less optimistic than the very last trend shows, by any means, all available forecasts published recently predict the TFR in Czechia and Slovakia to be clearly below the replacement level, even in high fertility scenarios. There is still some potential for recuperation, although the very crucial part of recuperation has already finished.

Only the medium scenario was used in the study because this is given as the most likely future trajectory and low together with high variants are only rough frontiers of future development. The high and low scenarios would complicate the explanations much. For instance, in case of a high scenario, fertility is closer to the communist level of fertility and mortality is an opposite case. As for the range, for instance the difference between the high and low scenarios in the case of the fertility level in the Slovak forecast is approximately 0.2 children in 2040 (1.65-1.85), so it is not a wide range. In the case of mortality, the range is between 77 and 80 for males and between 82 and 85 for females. There is an assumption that in the first decades the increase will be higher than in later decades, the potential for growth will be spending in the first period, mainly in higher ages in the case of both sexes. No confidence intervals in terms of percentage expressions were published in the forecasts.

Table 2 Overview of values of life expectancy in selected years

\begin{tabular}{|c|c|c|c|c|c|c|}
\hline & Real data, 1950 & Real data, 1989 & Real data, 2015 & $\begin{array}{l}\text { 1989-2018, simulation: } \\
\text { post-diction period }\end{array}$ & 2040, official forecast & $\begin{array}{l}\text { 2019-2040, simulation: } \\
\text { projection period }\end{array}$ \\
\hline \multicolumn{7}{|l|}{ Males } \\
\hline Czech R. & 62.30 & 68.10 & 75.20 & 68.10 & 81.30 & 68.10 \\
\hline Slovak R. & 58.96 & 66.88 & 72.90 & 66.88 & 79.70 & 66.88 \\
\hline \multicolumn{7}{|l|}{ Females } \\
\hline Czech R. & 67.00 & 75.40 & 81.10 & 75.40 & 86.60 & 75.40 \\
\hline Slovak R. & 62.76 & 75.36 & 79.61 & 75.36 & 84.90 & 75.36 \\
\hline
\end{tabular}


The assumptions in the official forecasts are the following. Both the Czech and Slovak forecasters see some potential for a slight increase in fertility from the levels of very-low fertility, driven by recuperation in the first period and convergence to the levels common for Western European countries (1.7-1.9). In general, the forecasters see no reasons for fertility being remained at such a low (current) level. The trend in life expectancy is positive and is assumed to stay growing in the coming decades, although this is indeed still only gaining the situation in Western Europe. The values in 2040 are expected to be only slightly higher than the current values in the countries such as France, Great Britain or Germany.

Migration was not incorporated into the model. Its impact on the dynamics was, and still is, not so significant as the impact of reproduction and population momentum. However, this is primarily a problem of obtaining reliable data. In particular, emigration is largely undocumented. A zero-migration variant, which we experimentally simulated as a check-point for the Slovak Republic, is only little different from the medium scenario. Thus, at least for the purposes of this study, which is a dichotomous comparison of two completely different trajectories, we can abstract from migration. Migration has a more significant impact on the number of population, but it does not influence significantly the indicators of ageing. As shown in studies on replacement migration, only hundreds of thousands to millions of immigrants would be able to reverse the increase of the mean age of the population in transition countries [23].

\section{Results}

Accuracy in the context of developmental turning points. Is there an assumption drag?

The key finding covers the fact that the forecasts did not react accurately enough in the case of both countries. This statement refers to all three processes representing the input parameters of the cohort-component model.

The percentage error of population size by age in the 1994 forecast for regions of the Slovak Republic is shown in Fig. 2. The error was calculated for the period of 6 years after the forecast threshold, i.e. for the year of 2000. Values on the left side clearly demonstrate how overestimated fertility was, which, in other words, shows an underestimation of real fertility descent. The number of children in the age-category $0-4$ years was overestimated by nearly $35 \%$ only 6 years after the forecast threshold. What may the sources of this error be? Fertility parameters had been derived from the expectations of the descent cessation. Only a temporary fertility downfall caused by the transformation shock, inflation, a sharp rise in the unemployment rate, fear of the population of the new situation had been considered.
According to recent generation data, a high rate of birth postponement appeared in the 1990s, peaking at the turn of the millennia. In 2001, the total fertility rate dropped below 1.2 children per woman in Slovakia; in some urbanised districts even below 1 child per woman. In 1993, however, the latest available data referred to 1.9 children per woman. In the following year, the total fertility rate reached only 1.67 , decreasing to only 1.52 in 1995. Indeed, the forecasters paid the price for the fact that the forecast was being made in the moment of a break and no most appropriate and fresh data were available. Therefore, this was not a pure assumption drag but also a trivial mischance. Two or 3 years later, with the statistical data already reporting on the downfall, the forecasters would have been able to generate more adequate predictions.

High PE values can be observed on the right-hand side of Fig. 2, i.e. in the senior age categories. The error might be explained by an overestimation of mortality rates, or by neglecting the trend of mortality rate decrease. Mortality decomposition by age may indicate that mortality rate for age categories $60+$ contributed to the prolongation of life expectancy after 1989. In 1993, the data on life expectancy of male population reported on increase by nearly 2 years compared to those in 1990 . Moreover, this increase was observed after a long period of life expectancy stagnation or even a temporary decrease in male categories. In the female population, life expectancy grew by 1.2 years which was slightly, but the growth rate was higher compared to that in the communist period. One year after the official forecast release (in 1995) and in the following years, a further descent of mortality rates appeared; however, this was not captured in the forecast. Despite the data reporting on a positive trend, the forecasters were bound by an assumption drag or certain inertial thinking. In the forecasters' perception, the life expectancy growth could not fit the drastic after-1989 economic measures.

We can compare our results with those in the study by Kučera [24]. This is a very comprehensive assessment of the Czechoslovak forecasts released within roughly three decades of the communist era from 1953 to 1987. Unlike post-1989 errors, the errors in mortality prediction are in forecasts published during the communist period much higher and the overall accuracy was induced mainly by mortality. According to his results, only one forecast published in 1971 underestimated markedly the population size because its assumptions did not predict a substantial increase in fertility at the beginning of 1970s. Thus, the major source of inaccuracy lies in mortality, mainly in the case of males, but the overall errors after 5 and 10 years are lower than in the case of the first post-1989 forecasts. This is mainly induced by the fact that the number of turning points and their amplitude 


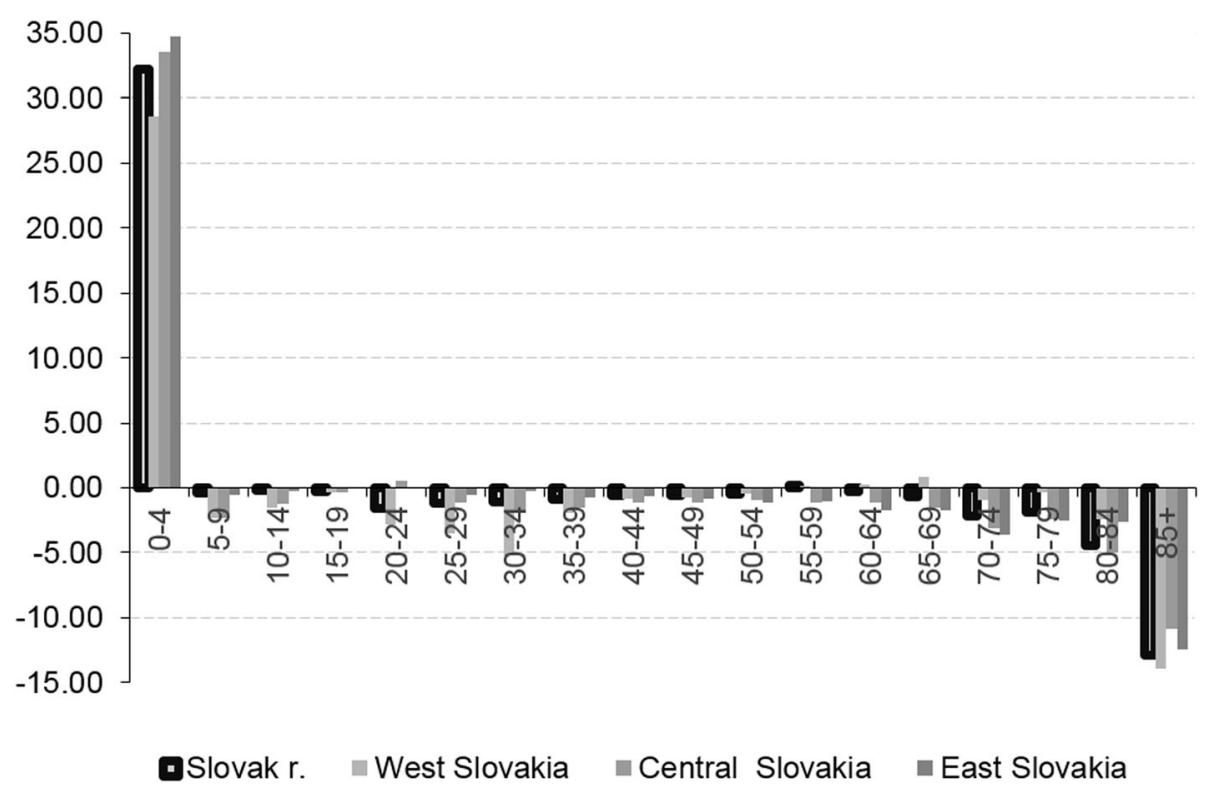

Fig. 2 Percentage error of population size by age in regions of the Slovak Republic. Source: [16], authors' simulation. Note: districts existing until 1996, calculated for year 2000 (6 years after threshold)

was generally lower in previous periods than in post1989 communist developments, and once occurred, they instantly affected the accuracy, for instance, the after1970 growth in fertility. Kučera [25] assessed also errors in regions (actually NUTS-3) and districts (actually LAU-1). He pointed out that the variability in the set of smaller geographical units is much higher, and this was confirmed also in our evaluation. To make the picture more comprehensive, we mention also one current analysis from Slovakia [26]. The accuracy of the national deterministic three-scenario-forecast from 2012 has been analysed until 2017. It should be remarked that the second decennium is a period of stabilisation bound to recuperation and slight increase from very-low fertility levels to levels close to the EU average and more. This is reflected in the results. The authors used Keyfitz's index of predictions' quality (see [27] for details) and stated that there is some underestimation of recuperation in the case of fertility, but the results are generally satisfying, especially in the case of mortality. The trends did justice to reality adequately. Although the 2012 forecast used a very detailed methodology, multi-decompositions and cohort approach, the main factor of relative success very likely lies also in the period when published and in ongoing years that can be marked as a "calm period".

Going back to the results of our evaluation, similar results at the NUTS-III-level regions can be observed in the forecast generated for the Czech Republic (Fig. 3). These errors demonstrate that the application of better models (different from those used) would have not brought any better results. The remarkable turning points and mainly unprecedented changes caused by the society transformation accompanied by a lack of information on the demographic substance of changes led to the forecasting failure. There was not time enough for any detailed analyses and the datasets referred only to a short timeline.

Figure 4 illustrates the PE in the total population size in the case of the districts of the Czech Republic 7 years after the forecast threshold. This refers to the territorial structure effective in the 1990s which would refer to the current LAU-2 level. In most of the districts, the population size was overestimated as a consequence of fertility rate overestimation. However, we can observe some exceptions represented by hinterlands of some large cities where population size was underestimated. This was caused by the emergence of new migration patterns. After WW2, a rapid urbanisation appeared in both Slovakia and the Czech Republic. In Slovakia, the urbanisation degree between 1950 and 1989 more than doubled. In 1950 , there were only $25 \%$ of urban population while in 1989 there were nearly 57\%. The urbanisation process was a centrally controlled procedure accompanied by industrialisation. Many former agrarian regions were equipped with new large industrial centres. In many rural communities, the population development was controlled and obstructed by the restriction of new housing development. Similarly to fertility and family behaviour patterns, migration patterns witnessed rapid changes, too. The new phenomenon of suburbanisation appeared here, being examined by geographers in both Slovakia and the Czech Republic. There have been 


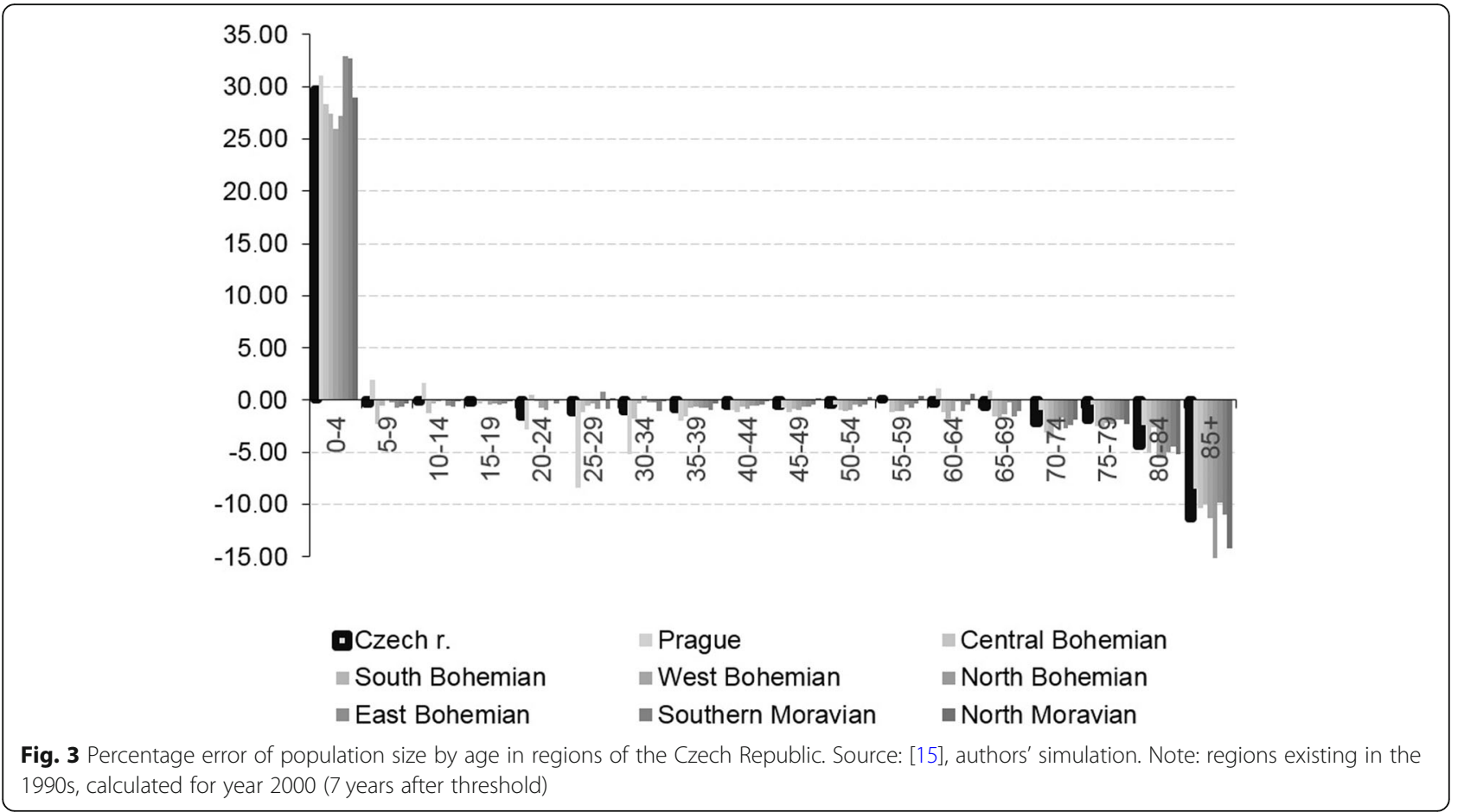

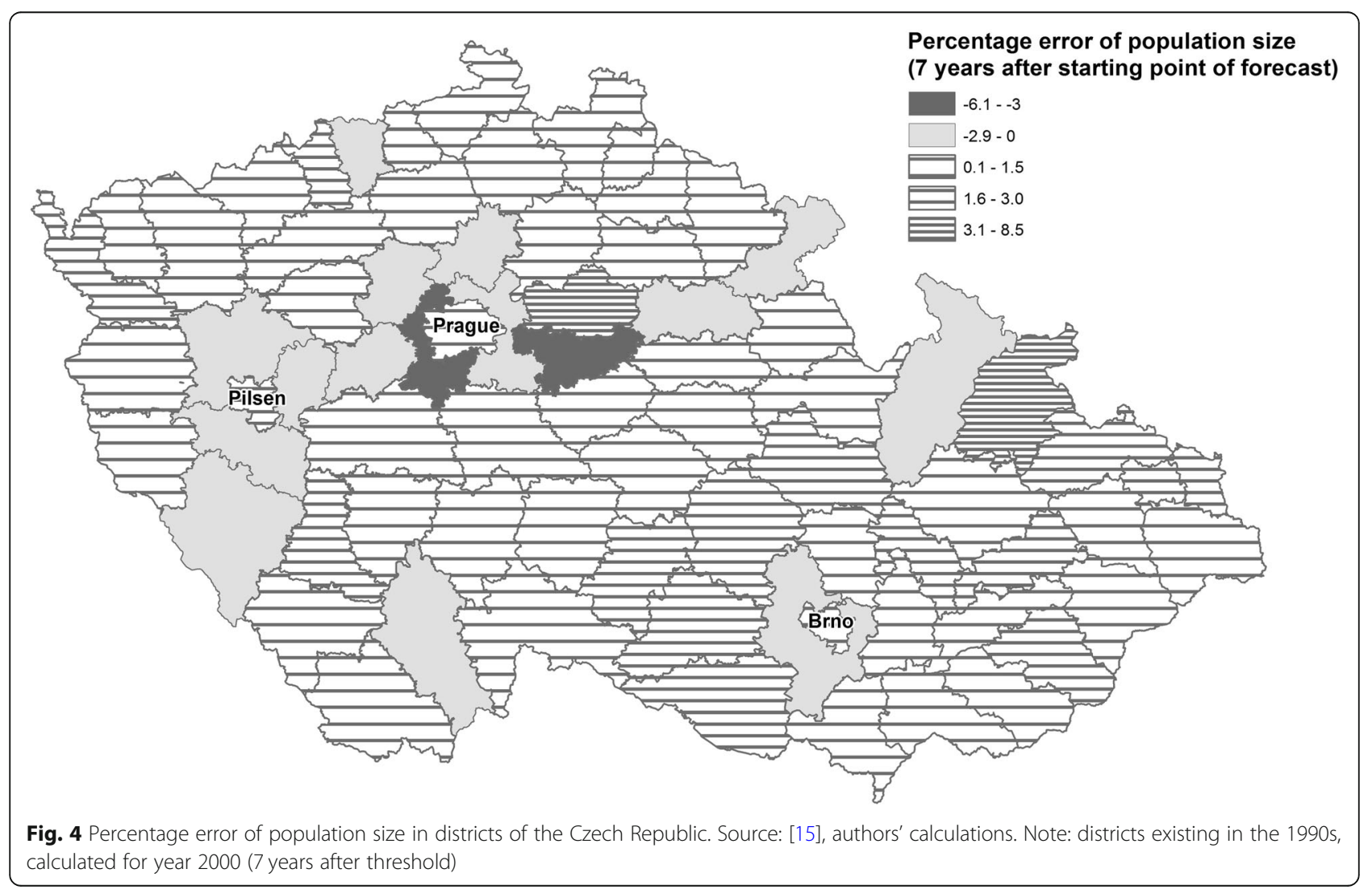


hundreds of studies focused on the phenomenon of suburbanisation. However, this issue was a pure terra incognita in the early 1990s. Demographers were not able to estimate when and to what scale the processes visible in Western Europe or the USA appear in a postcommunist society where they had been restricted or deformed by then regime. Significant part of the districts can be found in the intervals of overestimated population size due to a neglected fertility rate decline. In other districts, we can observe an error stemming from omitting the suburbanisation process and its impacts on migration patterns. This relates to the largest cities such as Prague or Brno, but also Pilsen. The districts forming the functional urban regions of these cities manifested an underpredicted population size as of 7 years after the initial point of the forecast, simply because no immigration had been predicted for these districts. Persistence of trends observed before 1989 had been predicted. The spatial pattern in Fig. 5 is therefore nearly homogeneous. As of 6 years after the forecast threshold, all districts (except for two) were afflicted by an overestimation of the population size. An unexpected fertility rate decline was the main reason.

\section{Alternative futures: post-1989 socio-economic transformation versus virtually outstaying communism}

The results of the simulation and its comparison against official forecasts are evaluated here. The main goal is to show the difference between a likely developmental trajectory from the official forecasts and a simulated trajectory coming from the socialistic continuum. This is a rather trivial exercise; however, it brings quite unique results pointed out in Figs. 6 and 7 and Table 3. They are summarised as follows.

a) The difference between the age structures (grey with no lines versus $\mathrm{B} / \mathrm{W}$ pyramids) is significant and contrastive. As expected, virtual populations (grey, continuing socialism up to 2040) are younger with a wider base. In contrast, the cohorts are less numerous in the older age categories. The pyramids therefore illustrate how fast fertility dominated ageing and ageing at the top has been due to after-1989 changes in fertility and mortality. The indicators such as mean age and ageing index demonstrate the huge differences. For instance, the index of ageing in 2040 in case of simulation is more than two times lower compared to the values extracted from the official forecasts.

b) Differences in 2040 are much bigger than those in 2025. This means that, over time, the differences resulting from the change of reproduction would cumulate. It is most visible in the age structure of Slovak population. The fall in fertility in the case of Slovakia was more significant compared to the Czech example. At the same time, secondary waves can be identified that would occur at the time of entry of women from the 1970s into reproductive age. These are numerous generations, when the impact of the large number of women of reproductive age (post-war baby boomers) and the pro-natalist

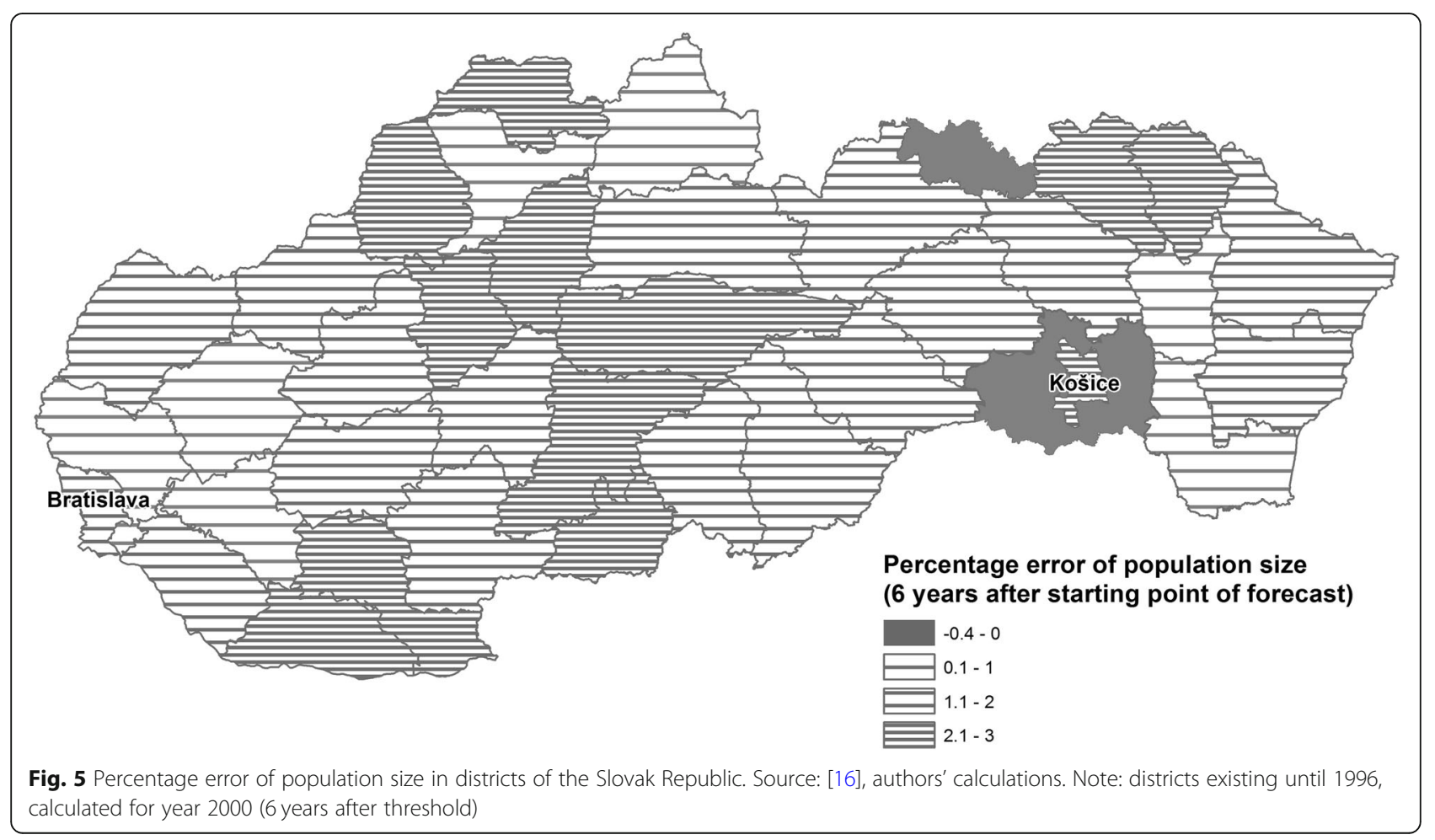



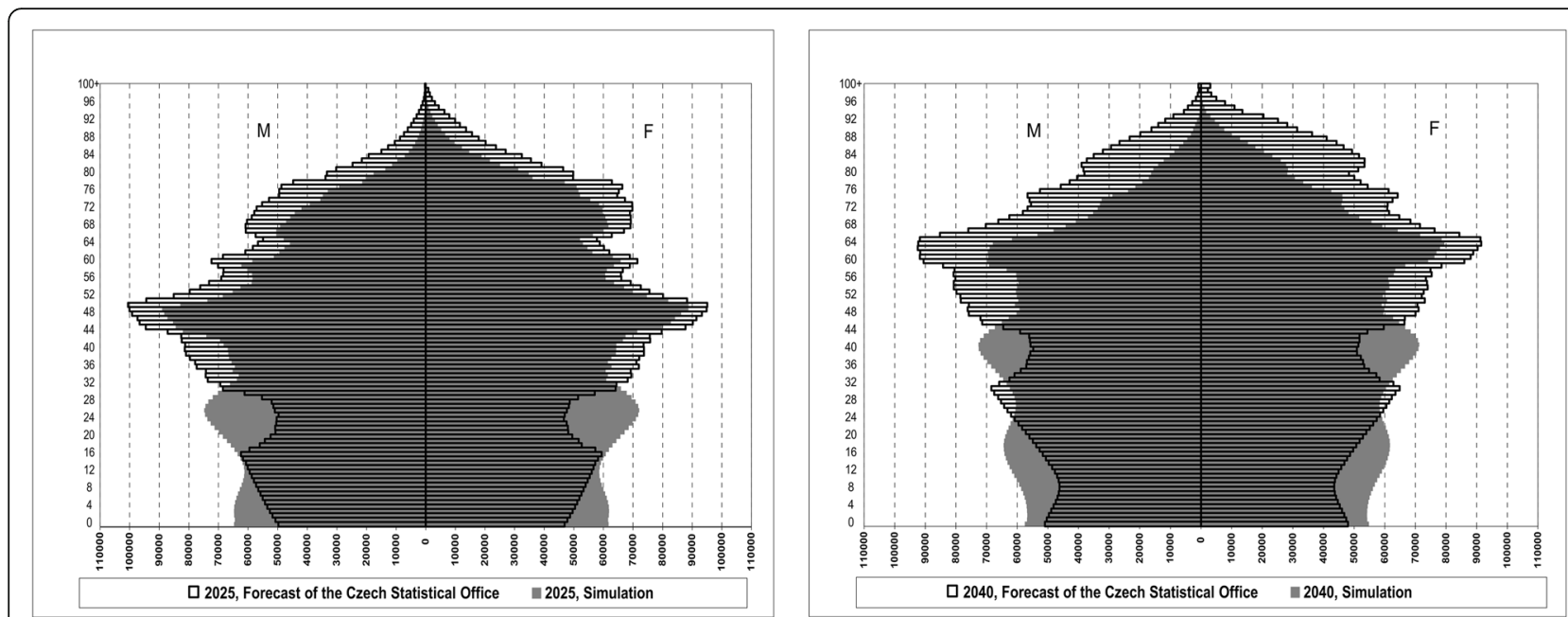

Fig. 6 Age structure of the Czech Republic-simulation versus official forecast. Source: [18], authors' calculations

measures of communist governments cumulated together. According to the then president, these children are sometimes referred to as "Husák's children". Due to a decline in fertility in the 1990s, this wave did not manifest itself, and, in the pyramid of Slovakia, there is a significant cut around the age of 35 years in 2040. The continuation of the reproductive regime typical for socialism characterised by fertility just above the replacement level would mean that, in 2040, a tertiary wave would also manifest. It is represented by population aged $15-20$ years in 2040. In these ages, the difference between the forecast and simulation is the highest one. Moreover, around 2050, these less numerous generations will reach the age of the most intensive reproduction, thus causing a further decrease in the number of births. Although the official forecast predicts an increase in the total fertility rate, the abovementioned age-structural effect will be more efficient. c) The differences between the simulated and officially forecasted populations are manifested in another way in the case of the Slovak Republic and the Czech Republic. Development in the twentieth century is the cause of a significant imbalance of age structure for the Czech Republic. Since fertility in the Czech Republic has been declining for a longer time, and in 1989, it was already lower than that in Slovakia, ageing at the base is not so significant. Thus, the difference between the officially forecasted and simulated populations is not so obvious as is in the case of Slovakia. The most significant difference lies in the age around 25 years in 2020 and 40 years in 2040. This is due to a significant fall in fertility from the turn of the millennia, when total fertility reached only 1.18 children per woman.

d) Concerning the birth rate, the difference between the predicted and simulated populations is much more obvious in the case of Slovakia, whereas in the case of
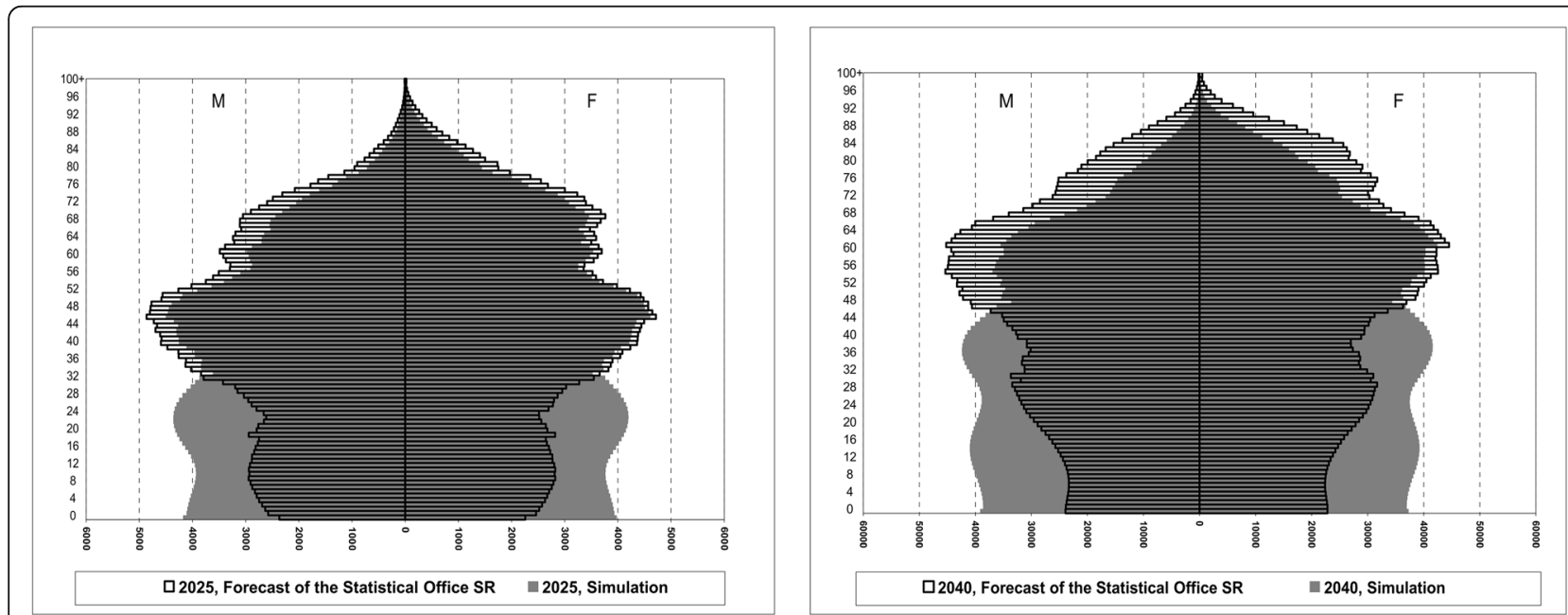

Fig. 7 Age structure of the Slovak Republic-simulation versus official forecast. Source: [19], authors' calculations 
Table 3 Age structure, comparison of the official forecasts and simulation in 2025 and 2040

\begin{tabular}{|c|c|c|c|c|}
\hline & Simulation, 2025 & Official forecast, 2025 & Simulation, 2040 & Official forecast, 2040 \\
\hline \multicolumn{5}{|l|}{ Czech R. } \\
\hline 0-14 (\%) & 17.9 & 14.9 & 17.6 & 12.9 \\
\hline 15-64 (\%) & 65.6 & 63.4 & 65.8 & 60.3 \\
\hline $65+(\%)$ & 16.4 & 21.7 & 16.6 & 26.8 \\
\hline $80+(\%)$ & 2.8 & 5.3 & 3.5 & 9.3 \\
\hline Ageing index & 91.7 & 145.6 & 94.1 & 208.3 \\
\hline Mean age & 39.6 & 43.9 & 40.2 & 47.0 \\
\hline \multicolumn{5}{|l|}{ Slovak R. } \\
\hline 0-14 (\%) & 19.7 & 14.9 & 19.5 & 12.6 \\
\hline $15-64(\%)$ & 65.6 & 66.0 & 65.0 & 62.4 \\
\hline $65+(\%)$ & 14.7 & 19.0 & 15.6 & 25.0 \\
\hline $80+(\%)$ & 2.6 & 3.7 & 3.7 & 7.4 \\
\hline Ageing index & 74.4 & 127.6 & 79.8 & 199.1 \\
\hline Mean age & 37.9 & 43.9 & 38.9 & 46.8 \\
\hline
\end{tabular}

Source: [18, 19], authors' calculations

mortality it is the opposite. A significant recent and expected future increase in life expectancy for men and women in the Czech Republic was reflected in the much more significant mortality-dominated ageing. The biggest difference between the officially forecasted and simulated populations of seniors is at the end of the simulated/forecasted period. Migration is likely to influence the difference between the simulated and officially forecasted age structures as the official forecasts include it and deal with a positive net migration mainly in productive ages (mainly in the case of males at ages around 40-60 years in 2040).

The differences between the Czech and Slovak populations confirm that the range of post-1989 impacts depends mostly on the stage in which the population met the transformational onset. The Slovak population was lagging behind the Czech one, and thus, the fall to the depopulation "mode" was steeper compared to the Czech case. An above-average fertility was positive during communism; however, the shift of big generations born in communist periods to a higher age in combination with the steeper downward trend in fertility changed the previous advantage into a burden.

\section{Conclusion}

Dissolution of the communist bloc and a bipolar world seems to be one of the most crucial turning points in the modern world's history. Societies in Central and Eastern Europe were facing rapid and extremely deep changes. Any social and economic predictions for the 1990s, rooted yet in the 1980s, certainly lost their validity. The analysis of the forecasts made in the early 1990s for what is now Slovakia and the Czech Republic showed a similar inaccuracy of predictions made at the initial stage of the post-communist transition period. Even though some initial data on rapidly changing demographic trajectories were available then, the forecasters were not able to incorporate them adequately. A certain inertial way of thinking could play its role, too. The post-communist countries such as Slovakia and the Czech Republic had existed in a certain demographic regime for a few decades. The fact that these changes were unprecedented may be the major argument to defend the demographers. Such rapid changes of a regime with such immense impacts had probably never been observed anywhere and anytime in the history. We can only assume that in this very case no sophisticated forecasting method could bring any more accurate results. The forecasters had no time for any detailed analyses, especially if a longitudinal approach was being applied. They had only poor information on the scale of birth postponement, and methods using tempoadjusted fertility rate calculation were to appear only at the turn of the millennia. As for migration, throughout a period of immense economic problems in the society, a growth in the unemployment rate and emergence of poverty, it was quite difficult to accept any prediction on a life-expectancy increase. Ironically, the growth in life expectancy was not lower or was lower only slightly during the first "aching" period than in the later, more successful, period from around 2000.

Therefore, an assumption drag first mentioned by Ascher [28] in this very case can be considered as natural and not surprising at all. This also confirms that making any forecasts in the period of turning points may be harmed by inaccuracies. Sophisticated methods are not very helpful in such a situation.

Empirical simulations have also shown that the effect of changes in the reproductive behaviour on the population dynamics and the changes in the age structure with 
two representatives of the post-socialist bloc were massive. Although a virtual continuation of communism would also have brought certain changes in fertility and mortality, it is certain that they would have not been so significant. Simulation thus indirectly suggests that the divergence of the West and the Eastern blocs of countries would have increased instead of convergence projected by the EUROSTAT projection [29]. One should mention that despite several converging patterns occurring after 1990, there are still some partial divergences or at least interrupted or slowing convergences within demographic components [30].

The Slovak and Czech populations would have been demographically much younger due to higher fertility and mortality in the conditions of socialism associated with pro-natalist measures and unfavourable health and medical conditions. Assuming stagnation or only a slight increase in life expectancy and only a slight decline in fertility, the almost exclusive impact on ageing would have been the shift of numerous cohorts of the 1950s and 1970s. Slovak population will be the oldest in the European Union in the second half of this century. Ironically, this can be true just thanks to the over-averaged dynamics until the 1980s that was higher than in the Czech Republic. Thus, the previous advantage changed itself into the burden in just a few decades.

\section{Acknowledgements}

Not applicable

\section{Originality}

I confirm that the article is original, has not already been published in a journal, and is not currently under consideration by another journal.

\section{Licence agreement}

I agree to the terms of the SpringerOpen Copyright and License Agreement.

\section{Author's contributions}

There are no co-authors for this manuscript. The author read and approved the final manuscript.

\section{Funding}

Slovak Research and Development Agency (Grant No. APW 17-0079)

\section{Availability of data and materials}

Data on personal request

Ethics approval and consent to participate

Not relevant for the study.

\section{Consent for publication}

The author agrees to publish the manuscript and there have been no individual data used.

\section{Competing interests}

The author declares that he has no competing interests..

Received: 18 February 2019 Accepted: 23 September 2019

Published online: 03 November 2019

\section{References}

1. Bongaarts J, Feeney G (1998) On the quantum and tempo of fertility. Popul Dev Rev 24:271-291
2. Keyfitz N (1981) The limits of population forecasting. Popul Dev Rev 7:579-593 3. Stoto AM (1983) The accuracy of population projections. J Am Stat Assoc 78:13-20

4. Smith SK (1987) Tests of forecasts accuracy and bias for county population projections. J Am Stat Assoc 82:991-1012

5. Smith SK, Sincich T (1991) An empirical analysis of the effect of length of forecast horizon on population forecast errors. Demography 28:261-274

6. Smith SK, Sincich T (1992) Evaluating the forecast accuracy and bias of alternative population projections for states. Int J Forecast 8:495-508

7. Sanderson W (1995) Predictability, complexity, and catastrophe in a collapsible model of population, development, and environmental interactions. Math Popul Stud 5:259-279

8. Tayman J, Smith SK, Lin J (2007) Precision, bias, and uncertainty for state population forecasts: an exploratory analysis of time series models. Popul Res Policy Rev 26:347-369

9. Rogers A (1995) Population forecasting: do simple models outperform complex models? Math Popul Stud 5:187-202

10. Keilman N (1997) Ex-post errors in official population forecasts in industrialized countries. J Off Stat 13:245-277

11. Keilman N, Kučera T (1991) The impact of forecasting methodology on the accuracy of national population forecasts: evidence from the Netherlands and Czechoslovakia. J Forecast 10:371-398

12. Potančoková M, Vaňo B, Pilinská V, Jurčová D (2008) Slovakia: fertility between tradition and modernity. Demogr Res 25:973-1018

13. Vaňo B (2001) The demographic characteristics of the Roma population in Slovakia. Infostat, Bratislava

14. Šprocha B, Bleha B (2018) Does Socio-Spatial Segregation Matter? 'Islands' of High Romany Fertility in Slovakia. Tijdschrift voor Economische en Sociale Geografie 109:239-255

15. Czech Statistical Office (1993) Projekce obyvatelstva České republiky do roku 2020, část II, ČR- kraje, okresy. (Population Projections of the Czech Republic until 2020, part II, Regions and Districts)

16. Statistical Office of the Slovak Republic (1994) Prognóza vývoja obyvatel'stva SR podla okresov vrátane migrácie. (Population forecast of districts in Slovakia including migration assumptions)

17. Swanson DA, Tayman J, Bryan MT (2011) MAPE-R: a rescaled measure of accuracy for cross-sectional subnational population forecasts. J Popul Res 28:225-243

18. Czech Statistical Office (2013) Population projection of the Czech Republic until 2100 https://www.czso.cz/csu/czso/projekce-obyvatelstva-ceskerepubliky-do-roku-2100-n-fu4s64b8h4/ Accessed 12 July 2015

19. Infostat (2013) Population forecast of the Slovak Republic until 2060. http:// www.infostat.sk/vdc/pdf/Prognoza2060.pdf/ Accessed 12 July 2015.

20. Hagget $P$ (1972) Geography: a modern synthesis. Harper and Row, London

21. Ellison CHJ, Mahoney JR, Crutchfield, JP (2009) Prediction, retrodiction, and the amount of information stored in the present. Santa Fe Institute Working Paper 09-05-XXX https://arxiv.org/pdf/0905.3587.pdf Accessed 15.6.2019

22. Šprocha B, Tišliar P, Šídlo L (2018) A cohort perspective on the fertinity postponement transition and low fertility in Central Europe. Moravian Geograph Rep 26:109-120

23. Burcin B, Drbohlav D, Kučera T (2005) Czech Republic in the mirror of replacement migration concept. Acta Universitatis Carolinae - Geographica 40:47-67

24. Kučera T (1998). Regionální populační prognózy: teorie a praxe prognózovaní vývoje lidských zdrojů v území. PhD Thesis, Charles University, Prague

25. Kučera T (1988) Les perspectives démographiques nationales et regionals en Tchécoslovaquie - es méthodes et la question de confiance. Acta Universitatis Carolinae - Geographica 23:57-71

26. Bleha B, Šprocha B, Vaňo B (2018) Prognóza obyvatel'stva Slovenska do roku 2060: Revízia poznatkov a predpokladov v kontexte pokračujúcej transformácie. Infostat, Bratislava

27. Keyfitz N, Caswell H (2005) Applied mathematical demography. Springer, New York

28. Ascher W (1978) Forecasting. An Appraisal for Policy-makers and Planners. John's Hopkins University Press, Baltimore

29. EUROSTAT (2008) EUROPOP 2008 convergence scenario https://ec.europa. eu/eurostat/statistics-explained/index.php?title=Archive:Population_ projections\&oldid=21953 Accessed 5 Apr 2019

30. Meslé F, Vallin J (2017) The end of east-west divergence in European life expectancies? An introduction to the special issue. Eur J Popul 33:615-627

\section{Publisher's Note}

Springer Nature remains neutral with regard to jurisdictional claims in published maps and institutional affiliations. 